\title{
Centering Ability of a New Nickel-Titanium Rotary Instruments with a Peculiar Flat-side Design: An In Vitro Study
}

\author{
Dario Di Nardo ${ }^{1}$, Gabriele Miccoli ${ }^{2}$, Alessandro Mazzoni ${ }^{3}$, Marco Seracchiani ${ }^{4}$, Gianluca Gambarini ${ }^{5}$, Luca Testarelli ${ }^{6}$
}

\begin{abstract}
Aim: The aim of the present study was to investigate the role of the flat design compared with a non-flat designed instrument on the centering ability in a simulated root canal system.

Materials and methods: Two file systems were chosen: the F-One (Fanta Dental, Shanghai, China) and a prototype with the same design but without the flat-side design. A total of 50 simulated L-shaped root canals in resin blocks were shaped with a new instrument each. Pre- and post-canal preparation images were captured and superimposed to measure and compare the canal transportation and evaluate the centering ability of each file. The $t$ test was performed and the level of significance was set at $p<0.05$.

Results: Prototype files removed significantly less resin from the inner and the outer parts of the canal and showed significantly higher mean transportation values.

Conclusion: It can be concluded that the F-One file system demonstrated better shaping ability compared with the prototype file system in L-shaped resin-simulated canals.

Clinical relevance: The present study showed the safety of the flat-side design, minimizing the risk of iatrogenic errors such as ledging, perforation, or zipping of the root canal.

Keywords: Canal centering ability, Canal transportation, Endodontics, NiTi rotary instrument, Root canal shaping.

The Journal of Contemporary Dental Practice (2020): 10.5005/jp-journals-10024-2829
\end{abstract}

\section{INTRODUCTION}

Root canal shaping is a crucial procedure in endodontic treatment that influences the subsequent steps of root canal disinfection and obturation. Forming a continuously tapering channel from the coronal access cavity to the root apex, ensuring the location of the apical canal anatomy, and preserving the original canal shape are the principal keys of the root canal treatment. ${ }^{1}$ Since their introduction, nickel-titanium ( $\mathrm{NiTi}$ ) rotary instruments have considerably simplified endodontic procedure, reducing the number of instruments used. This allows faster treatment meanwhile reducing risk of iatrogenic errors. ${ }^{2}$

However, the procedural errors during instrumentation such as ledging, zipping, perforations, root canal transportation, and instrument separation could happen, especially when preparing curved canals. ${ }^{3,4}$ Manufacturers provided new heat treatments and different cross-sectional design with the aim to improve accuracy and safety of root canal shaping and to reduce instrumentation time.

Nickel-titanium rotary instruments could be tested using a dynamic or static procedure. In literature, most of the published articles use the static test such as cyclic fatigue resistance and torsional failure. ${ }^{5-7}$ Unfortunately, these tests are not able to mimic the operative clinical condition. For this reason, a dynamic evaluation of a NiTi rotary files during intra-canal instrumentation is often recommended and could be performed evaluating the shaping ability of the instrument.

The shaping or centering ability is defined as the ability of an instrument to remain centered in the root canal system during intra-canal instrumentation. ${ }^{8,9}$ It is one of the parameters

\begin{abstract}
${ }^{1-6}$ Department of Oral and Maxillofacial Sciences, Sapienza University of Rome, Rome, Italy

Corresponding Author: Marco Seracchiani, Department of Oral and Maxillofacial Sciences, Sapienza University of Rome, Rome, Italy, Phone: +39 3343795174, e-mail: marco.seracchiani@gmail.com

How to cite this article: Di Nardo D, Miccoli G, Mazzoni A, et al. Centering Ability of a New Nickel-Titanium Rotary Instruments with a Peculiar Flat-side Design: An In Vitro Study. J Contemp Dent Pract 2020;21(5):539-542.
\end{abstract}

Source of support: Nil

Conflict of interest: None

more frequently used to know the performance of an endodontic rotary file.

Recently, a new thermally treated NiTi rotary instrument, F-One (Fanta Dental), characterized by a flat designed and S-shaped cross section has been developed. These characteristics confer lots of advantages such as reducing blade engagement, increasing fatigue lifespan, and taking out the debris from the prepared area.

The instrument presenting an S-shaped cross-sectional design has two active cutting points and a non-cutting tip. Moreover, the F-One (Fanta Dental) is a single-file system and presents a new heat treatment called AF-R wire, which, according to the manufacturer internal studies, should provide more cutting efficiency and higher cyclic fatigue and torsional resistance than other NiTi files.

Many studies investigated the role of S-shaped cross-sectional design on cyclic and torsional fatigue resistance and shaping

(0) The Author(s). 2020 Open Access This article is distributed under the terms of the Creative Commons Attribution 4.0 International License (https://creativecommons. org/licenses/by-nc/4.0/), which permits unrestricted use, distribution, and non-commercial reproduction in any medium, provided you give appropriate credit to the original author(s) and the source, provide a link to the Creative Commons license, and indicate if changes were made. The Creative Commons Public Domain Dedication waiver (http://creativecommons.org/publicdomain/zero/1.0/) applies to the data made available in this article, unless otherwise stated. 
ability. ${ }^{10,11}$ To date, no studies in the literature have evaluated the influence of flat design on the centering ability of an instrument.

To avoid any risk of bias and to properly evaluate the influence of cross-sectional design on centering ability, the instruments should be compared with similar ones that present same characteristics. For these reasons, the manufacturer (Fanta Dental) was asked to provide a prototype made with the same characteristics such as heat treatment, design, pitch, blade angle, and cross section of the F-One that differed only by the absence of the flat sides.

The aim of the present study was to investigate the role of the flat design compared with a non-flat designed instrument on the centering ability in a simulated root canal system.

\section{Materials and Methods}

\section{Sample Selection}

A total of 50 simulated L-shaped root canals in resin blocks (Endo Training Bloc; Dentsply, Maillefer, Tulsa, USA) were selected in this study. These resin blocks were then randomly assigned into two equal experimental groups (group I: F-One, $n=25$; group II: prototype, $n=25$ ), based on the NiTi rotary file system used for the preparation of canal type.

The standardization of each resin block was ensured by considering canal length $16 \mathrm{~mm}$, diameter of apical foramen $0.15 \mathrm{~mm}$, initial taper 0.2 , coronal radius $6 \mathrm{~mm}$, and Schneider's angle of curvature $35^{\circ}$. Each simulated canal was prepared using a new nonused instrument.

\section{Canal Preparation Evaluation}

Before the instrumentation of the resin blocks, all simulated canals were stained with Carbon Black ink (Faber-Castell, Stein, Germany) using a 30-gauge insulin syringe. K-file no. 8 (Dentsply) was inserted into the canal to allow uniform penetration of the ink in the simulated canal system and to prevent air bubble formation. To guarantee image standardization and eliminate distortion, a stable platform for mounting camera was at a fixed distance and at an angle of $90^{\circ}$ to the resin block. Pre- and post-canal preparation images were captured using a digital camera (Canon EOS D400, Tokyo, Japan), and the images were superimposed. ${ }^{12}$

The instrument used to prepare the canals of group I was F-One with 25 tip and 0.04 constant taper, and the prototype, with the same tip and taper, was used to prepare the canals of group II. The instruments were rotated at $350 \mathrm{rpm}$ and $2 \mathrm{~N} \mathrm{~cm}$ torque using an endodontic motor (X-Smart Plus; Dentsply, Ballaigues, Switzerland). When the maximum torque was reached, the instruments were removed from the canal, and the canal debris was flushed out using copious amount of distilled water with a 27-gauge needle. Flutes of the files were cleaned with gauze wetted with Glyde agent (RC Prep; Premier Dental Products Company, Plymouth Meeting, USA) after every usage.

At the end of canal preparation, Garnet Red ink (Faber-Castell) was filled in every canal. A postoperative photograph was taken in the same position of the preoperative photograph to ensure the superimposition. Pre- and post-canal instrumentation images were superimposed to create a single image using Photoshop CC 2015.5 (Adobe System, Inc., San Jose, CA, USA) (Fig. 1). ${ }^{13}$

All the canal preparations were performed by the same operator, and using the superimposed image, root canal aberrations such as apical zipping, elbow formation, canal ledge, and perforation were researched.

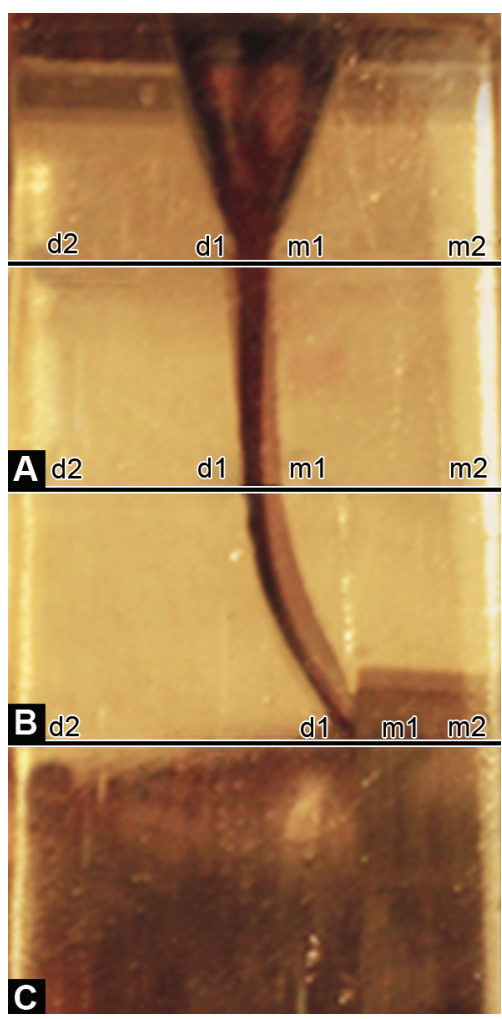

Figs $1 \mathrm{~A}$ to $\mathrm{C}$ : Superimposition image of the L-shaped resin block canal. (A to C) The image shows three levels of analysis

Measurement of widths was carried out using the superimposed images at three different positions evaluating the distance between the inner aspect of the canal and the outer surface of the resin blocks. The measurements were made with the Photoshop CC 2015.5 digital millimetric ruler, setting the width of the resin block as the reference system.

The positions taken in consideration were:

- Canal orifice;

- Beginning of the curvature;

- End of artificial canal.

\section{Data Analysis}

All the collected data were entirely analyzed using the Statistical Package for the Social Sciences (IBM-SPSS, version 23, Shanghai, China). Centering ratio and canal transportation were calculated in each position using the following equation: centering ratio: $\left(m_{1}-m_{2}\right) /\left(d_{1}-d_{2}\right)$; canal transportation: $\left(m_{1}-m_{2}\right)-\left(d_{1}-d_{2}\right) \cdot{ }^{14}$ The $m_{1}$ is the distance from the mesial position of the non-instrumented canal to the resin block wall, the $m_{2}$ is the same distance from the instrumented canal. The same operation was performed at the distal position forming the $d_{1}$ and $d_{2}$ distances. ${ }^{15}$

The $t$ test was performed, and the level of significance was set at $p<0.05$.

\section{Results}

All the tested instruments used in this study prepared the canal successfully with no separation during instrumentation. No one causes any canal aberrations such as ledging, zipping, and perforations. 
Table 1: Mean amount of material removed from the inner and outer aspects of the root canals ( $\mathrm{mm}$ )

\begin{tabular}{lllll}
\hline & & $A$ & $B$ & $C$ \\
\hline Removed material from the inner & Flat (mean \pm SD) & $0.240 \pm 0.19$ & $0.318 \pm 0.09$ & $0.128 \pm 0.01$ \\
aspect & Prototype (mean \pm SD) & $0.254 \pm 0.07$ & $0.346 \pm 0.08$ & $0.138 \pm 0.01$ \\
Removed material from the outer & Flat (mean \pm SD) & $0.182 \pm 0.12$ & $0.112 \pm 0.05$ & $0.204 \pm 0.09$ \\
aspect & Prototype (mean \pm SD) & $0.218 \pm 0.07$ & $0.120 \pm 0.02$ & $0.356 \pm 0.21$ \\
\hline
\end{tabular}

Level of significance was set at $p<0.05$

Table 2: Mean centering ability and canal transportation ( $\mathrm{mm}$ )

\begin{tabular}{llrll}
\hline & & \multicolumn{1}{l}{ A } & \multicolumn{1}{l}{ B } & \multicolumn{1}{l}{$C$} \\
\hline Canal transportation & Flat (mean \pm SD) & $0.046 \pm 0.032$ & $0.166 \pm 0.117$ & $0.052 \pm 0.034$ \\
& Prototype (mean \pm SD) & $0.05 \pm 0.038$ & $0.202 \pm 0.150$ & $0.054 \pm 0.074$ \\
& $p$ values & & & \\
Centering ratio & Flat (mean \pm SD) & $1.276 \pm 0.224$ & $2.252 \pm 0.966$ & $1.870 \pm 0.969$ \\
& Prototype (mean \pm SD) & $0.971 \pm 0.742$ & $0.182 \pm 2.041$ & $1.432 \pm 0.661$ \\
\hline
\end{tabular}

Level of significance was set at $p<0.05$

As shown in Table 1, the mean amount of material removed from the inner and outer aspects of the root canals was calculated.

The independent $t$ test $(p<0.05)$ shows that for all the three positions taken in examination, group II (prototype) removed a greater amount of resin than group I (F-One). These amounts were calculated measuring the canal width.

Both groups caused transportation at all the three levels (Table 2). The mean transportation values of group II were greater than group I at all the levels.

The $t$ test revealed that the differences were statistically significant $(p<0.05)$.

Table 2 also presents the means and standard deviations (SDs) of centering ratios of groups I and II. Significant greater values were detected at all the three levels of group I compared with group II regarding the centering ratio.

\section{Discussion}

The comparison of shaping ability is usually performed using extracted human teeth or resin blocks.

Natural teeth present a high variability in the shape, size and dimension of the root canal system. ${ }^{16,17}$ To asses a precise measurement, natural teeth should be studied with microcomputed tomography, a very expensive three-dimensional examination. Moreover, the impossibility to standardize dentin hardness and anatomical irregularities such as enlargement and bottleneck may influence the results not allowing a repetitive test.

For these reasons, the usage of resin blocks was preferred in this study. Although resin is not able to mimic human teeth due to much lower surface hardness compared with dentin. The main advantage of resin blocks is the possibility to standardize the characteristics of simulated root canals such as apex diameter, curvature angle, length, width, and radius of curvature. The drawback of the different hardnesses between resin and dentin walls is overcome by the standardization of the experimental conditions, allowing a predictable method evaluation and a reliability with clinical practice.

Indeed, the performance of rotary instruments has been related with their ability to respect original canal anatomy. Superimposed pre- and post-preparation images of prepared L-shaped resin blocks were used in the present study. ${ }^{18}$ This technique allows a precise dimensional quantitative and qualitative measurement. To eliminate influences due to kinematic both instruments were rotated with the same motor, motion, speed, and torque. ${ }^{19}$

Newly manufactured thermomechanically treated alloy, such as the AF-R wire (Fanta Dental), provided superior characteristics of flexibility and fatigue resistance to the files. ${ }^{5}$

However, limited studies have been undertaken to assess the influence of the flat properties on shaping ability of these new rotary files.

In the present study, the measurements were conducted at three different points, the canal orifice, the beginning of the curvature, and the end of artificial canal. During root canal preparation, the position and shape of apical foramen must be maintained in order to produce an ideal seal.

However, all the preparation instruments change the position of root canals. ${ }^{20}$

The results of the present study showed significant differences between the two tested instruments in all the three points taken in examination. Moreover the F-One presented an increased centering ability than the prototype. These results could be explained by the flat-side design since it reduces the presence of metal mass on the instrument, increasing flexibility, and cyclic fatigue resistance also allowing a more centered canal preparation. ${ }^{21,22}$

Moreover, the less blade engagement, due to the flat cross section of the instrument, could also explain a more conservative shaping ability of the instrument. ${ }^{23,24}$

The F-One produced less straightening of the canal curvature, and it was considered to have superior shaping ability because of less canal transportation and better perseveration of the original canal anatomy.

\section{Conclusion}

Within the limitations of the study, it can be concluded that the F-One file system demonstrated better shaping ability compared to the prototype file system in L-shaped resin-simulated canals. Moreover, this study underlines the potential of flat surface on instrument design opening up the possibility of developing new instruments trading on this peculiar characteristic. Further studies are needed to explore the potential of the above-mentioned flatside design to evaluate its clinical behavior, i.e., operative torque, 
and other metallurgical properties such as torsional resistance and cutting efficiency to confirm the potential already found in the current study.

\section{Clinical Significance}

The present study showed the safety of the flat-side design, minimizing the risk of iatrogenic errors such as ledging, perforation, or zipping of the root canal.

\section{References}

1. Allison DA, Weber CR, Walton RE. The influence of the method of canal preparation on the quality of apical and coronal obturation. $J$ Endod 1979;5(10):298-304. DOI: 10.1016/S0099-2399(79)80078-3.

2. Gambarini G, Miccoli G, Seracchiani M, et al. Fatigue resistance of new and used nickel-titanium rotary instruments: a comparative study. Clin Ter 2018;169(3):e96-e101.

3. Hendi SS, Karkehabadi H, Eskandarloo A. latrogenic errors during root canalinstrumentation performed by dental students. Iran Endod J 2018;13(1):126-131.

4. Madani Z, Soleymani A, Bagheri T, et al. Transportation and centering ability of Neoniti and ProTaper instruments; A CBCT assessment. Iran Endod J 2017;12(1):43-49.

5. Gambarini G, Galli M, Di Nardo D, et al. Differences in cyclic fatigue lifespan between two different heat treated NiTi endodontic rotary instruments: WaveOne Gold vs EdgeOne Fire. J Clin Exp Dent 2019;11(7):e609-e613. DOI: 10.4317/jced.55839.

6. Gambarini G, Seracchiani M, Piasecki L, et al. Measurement of torque generated during intracanal instrumentation in vivo. Int Endod J 2019;52(5):737-745. DOI: 10.1111/iej.13042.

7. Staffoli S, Grande NM, Plotino G, et al. Influence of environmental temperature, heat-treatment and design on the cyclic fatigue resistance of three generations of a single-file nickel-titanium rotary instrument. Odontology 2019;107(3):301-307. DOI: 10.1007/s10266018-0399-5.

8. de Albuquerque MS, Nascimento AS, Gialain IO, et al. Canal transportation, centering ability, and dentin removal after instrumentation: a micro-CT evaluation. J Contemp Dent Pract 2019;20(7):806-811. DOI: 10.5005/jp-journals-10024-2601.

9. Poly A, AlMalki F, Marques F, et al. Canal transportation and centering ratio after preparation in severely curved canals: analysis by microcomputed tomography and double-digital radiography. Clin Oral Investig 2019;23(12):4255-4262. DOI: 10.1007/s00784-019-02870-8.

10. Mesgarani A, Hamidi MR, Haghanifar S, et al. Comparison of apical transportation and centering ability of Mtwo and Reciproc R25 in severely curved canals using cone-beam computed tomography. Dent Res J 2018;15(1):57-62. DOI: 10.4103/1735-3327.223620.

11. Plotino G, Grande NM, Testarelli L, et al. Cyclic fatigue of reciproc and reciproc blue nickel-titanium reciprocating files at different environmental temperatures. J Endod 2018;44(10):1549-1552. DOI: 10.1016/j.joen.2018.06.006.

12. Wu H, Peng C, Bai Y, et al. Shaping ability of ProTaper Universal, WaveOne and ProTaper Next in simulated L-shaped and S-shaped root canals. BMC Oral Health 2015;15(1):27. DOI: 10.1186/s12903-0150012-z.

13. Keskin C, Demiral M, Sarıyılmaz E. Comparison of the shaping ability of novel thermally treated reciprocating instruments. Restor Dent Endod 2018;43(2):e15. DOI: 10.5395/rde.2018.43.e15.

14. Donnermeyer D, Viedenz A, Schäfer E, et al. Impact of new crosssectional designs on the shaping ability of rotary NiTi instruments in S-shaped canals. Odontology 2019;108(2):174-179. DOI: 10.1007/ s10266-019-00450-6.

15. Troiano G, Dioguardi M, Cocco A, et al. Increase in [corrected] the glyde path diameter improves the centering ability of F6 Skytaper. Eur J Dent 2018;12(1):89-93. Erratum in: Eur J Dent 2018;12(3):467. DOI: 10.4103/ejd.ejd_231_17.

16. Valenti-Obino F, Di Nardo D, Quero L, et al. Symmetry of root and root canal morphology of mandibular incisors: A cone-beam computed tomography study in vivo. J Clin Exp Dent 2019;11(6):e527-e533. DOI: 10.4317/jced.55629.

17. Gambarini G, Piasecki L, Ropini P, et al. Cone-beam computed tomographic analysis on root and canal morphology of mandibular first permanent molar among multiracial population in Western European population. Eur J Dent 2018;12(3):434-438. DOI: 10.4103/ ejd.ejd_116_18.

18. Çelik G, Maden M, Savgat A, et al. Shaping ability of the profile $25 / 0.06$ and protaper $\mathrm{F} 2$ in rotary motion, and reciproc in simulated canals. PeerJ. 2018;6:e6109. DOI: 10.7717/peerj.6109.

19. Kwak SW, Lee CJ, Kim SK, et al. Comparison of screw-in forces during movement of endodontic files with different geometries, alloys, and kinetics. Materials 2019;12(9):e1506. DOI: 10.3390/ma12091506.

20. Hiran-us S, Pimkhaokham S, Sawasdichai J, et al. Shaping ability of ProTaper NEXT, ProTaper Universal and iRace files in simulated S-shaped canals. Aust Endod J 2016;42(1):32-36. DOI: 10.1111/ aej.12117.

21. Gambarini G, Miccoli G, Seracchiani M, et al. Role of the flat-designed surface in improving the cyclic fatigue resistance of endodontic NiTi rotary instruments. Materials 2019;12(16):e2523. DOI: 10.3390/ ma12162523.

22. Di Nardo D, Galli M, Morese A, et al. A comparative study of mechanical resistance of two reciprocating files. J Clin Exp Dent 2019;11(3):e231-e235. DOI: 10.4317/jced.55487.

23. Ferreira FG, Barbosa IB, Scelza P, et al. Noncontact three-dimensional evaluation of surface alterations and wear in NiTi endodontic instruments. Braz Oral Res 2017;31:e74. DOI: 10.1590/1807-3107bor2017.vol31.0074.

24. Ferreira F, Barbosa I, Scelza P, et al. A new method for the assessment of the surface topography of NiTi rotary instruments. Int Endod J 2017;50(9):902-909. DOI: 10.1111/iej.12707. 